\title{
Requeijão cremoso probiótico: avaliação da viabilidade de Lactobacillus casei, da composição físico-química e aceitação sensorial
}

\section{Probiotic "requeijão cremoso": evaluation of Lactobacillus casei viability, physical-chemical composition and sensory acceptance}

\author{
Vanessa de Oliveira Gaino루 ${ }^{1}$ Verônica Parassen Voltarelli ${ }^{1}$; Christiane Maciel \\ Vasconcellos Barros de Rensis²; Priscila Cristina Bizam Vianna ${ }^{2 *}$
}

\section{Resumo}

O objetivo deste trabalho foi a elaboração de um requeijão cremoso probiótico, que mantenha as características físico-químicas e sensoriais do produto tradicional, agregando propriedades funcionais. Foi produzido um requeijão cremoso controle (sem a adição de probiótico) e outro adicionado de Lactobacillus casei, após a fusão da massa, à temperatura de $50 \pm 1^{\circ} \mathrm{C}$. Os requeijões controle e probiótico foram envasados, armazenados a $4 \pm 1^{\circ} \mathrm{C}$ e submetidos às análises de composição centesimal após 1 dia de processamento. $\mathrm{O}$ pH dos requeijões, assim como a contagem de Lactobacillus casei do requeijão probiótico foram avaliados após 1, 7, 14 e 28 dias de fabricação. A avaliação sensorial foi realizada no $4^{\circ}$ dia de armazenamento e os atributos analisados foram: aparência, sabor, aroma, textura, aceitação geral e intenção de compra. Os resultados foram avaliados por análise de variância e teste de médias de Tukey. Não houve diferença quanto à composição centesimal entre o requeijão controle e o requeijão

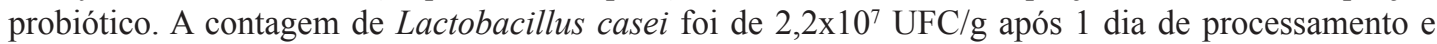
manteve-se constante durante os 28 dias de armazenamento a $4 \pm 1^{\circ} \mathrm{C}$. O requeijão probiótico apresentou boa aceitação sensorial e $82 \%$ dos provadores certamente ou provavelmente comprariam o produto. Os resultados permitem concluir que o requeijão pode ser considerado uma boa alternativa de produto lácteo probiótico.

Palavras-chave: Lactobacillus casei, probiótico, requeijão, sensorial

\begin{abstract}
The objective of this work was the production of probiotic "requeijão cremoso" that keeps the physicalchemical and sensorial characteristics of the tradicional product, linked to the functional properties. Control (without probiotic addition) and probiotic "requeijão cremoso" added with Lactobacillus casei after fusion, at $50 \pm 1^{\circ} \mathrm{C}$, were produced, packed and stored at $4 \pm 1^{\circ} \mathrm{C}$. Control and probiotic "requeijão cremoso" were evaluated to physical-chemical composition 1 day after processing. After 1, 7, 14 and 28 days of storage, the $\mathrm{pH}$ were evaluated for both products and Lactobacillus casei count only for probiotic "requeijão cremoso". Sensory evaluation was accomplished on the $4^{\text {th }}$ day of storage for appearance, taste, flavor, texture, general acceptance and purchasing intention. The results were evaluated by analysis of variance and Tukey's test. There was no difference on physical-chemical composition of control and probiotic "requeijão cremoso". Lactobacillus casei count was 2,2x10 $\mathrm{UFC} / \mathrm{g}$ after 1 day of
\end{abstract}

\footnotetext{
${ }^{1}$ Bolsista Iniciação Científica Funadesp, Curso de Graduação em Engenharia de Alimentos, Universidade Norte do Paraná, UNOPAR, Londrina, PR. E-mail: van_gaino@hotmail.com; ve_voltarelli@hotmail.com

${ }^{2}$ Profs. Pesquisadores do Mestrado em Ciência e Tecnologia do Leite, UNOPAR, Londrina, PR. E-mail: christiane@unopar.br; priscila.vianna@unopar.br

* Autor para correspondência
} 
processing and not showed significant variations during the 28 days of storage. The probiotic "requeijão cremoso" presented good sensory acceptance and $82 \%$ of the consumers certainly or probably buy the probiotic product. The results showed that "requeijão cremoso" may regard as a good alternative of probiotic product.

Key words: Lactobacillus casei, probiotic, requeijão cremoso, sensorial

\section{Introdução}

Segundo a legislação brasileira "Requeijão é o produto obtido da fusão da massa coalhada, cozida ou não, dessorada e lavada, obtida por coagulação ácida e/ou enzimática do leite opcionalmente adicionada de creme de leite e/ou manteiga e/ ou gordura anidra de leite ou butteroil. O produto poderá estar adicionado de condimentos, especiarias e outras substâncias alimentícias" (BRASIL, 1997).

O requeijão é um produto típico brasileiro, fabricado em quase todo território nacional, com suas variações de tecnologia e características que diferem de região para região. $\mathrm{O}$ produto requeijão encontra-se no mercado com diversos teores de umidade, do cremoso até o bastante firme, possível de ser cortado em fatias, como o requeijão do Norte. Um requeijão cremoso apresenta em média $45 \%$ de umidade, $30 \%$ de gordura, $23 \%$ de proteína, $2 \%$ de sal e pH entre 5,3-5,5 (OLIVEIRA, 1990).

Segundo suas características, o requeijão pode ser classificado como um queijo processado. Sua fabricação inclui as etapas de trituração da massa obtida por coagulação ácida ou enzimática, mistura dos demais ingredientes da formulação (creme de leite, sal, água e sal fundente) seguido do aquecimento e agitação intensa para a fusão da massa. A característica sensorial de um queijo processado é distinta de outros queijos devido ao tratamento térmico aplicado e aos sais fundentes utilizados (WALSTRA; WOUTERS; GEURTS, 2006).

Os sais fundentes ou emulsificantes comumente utilizados na fabricação de queijos processados, como o requeijão, são os citratos e polifosfatos de sódio, separadamente ou em misturas prontas. Estes sais tem a função de aumentar o pH e de diminuir o teor de cálcio iônico (sequestrar cálcio). A troca de sais de cálcio da matriz de paracaseína pelos sais de sódio (do sal fundente) promove a formação de paracaseinato de cálcio, melhorando a capacidade de ligar água da proteína. Assim, durante o processamento, os sais fundentes promovem a emulsificação da gordura livre e a reidratação da proteína contribuindo para a formação de um produto cremoso, homogêneo e estável (FOX et al., 2000).

Probióticos são micro-organismos vivos, administrados em quantidades adequadas, que conferem benefícios à saúde do hospedeiro (FAO, 2006). O interesse comercial na exploração dos atributos de saúde propostos pelos probióticos tem contribuído de uma forma significante para o rápido crescimento e expansão deste setor no comércio (STANTON et al., 1998).

As culturas probióticas adicionadas a produtos alimentares proporcionam benefícios para a saúde e nutrição do homem. O emprego de bactérias láticas em alimentos é de longa data e a maioria das cepas empregadas é considerada micro-organismos comensais, sem potencial patogênico (OLIVEIRA et al., 2002). Entre os diversos gêneros que integram o grupo de culturas probióticas usados em alimentos, destacam-se o gênero Bifidobacterium e o Lactobacillus. Os probióticos aprovados pela Anvisa (Agência Nacional de Vigilância Sanitária, 2008) são: Lactobacillus acidophilus, Lactobacillus casei shirota, Lactobacillus casei var rhammnosus, Lactobacillus casei var defensis, Lactobacillus paracasei, Lactococcus lactis, Bifidobacterium bifidum, Bifidobacterium animallis, Bifidobacterium lactis, Bifidobacterium longum e Enterococcus faecium (ANVISA, 2008). 
Os benefícios relacionados com a ingestão de probióticos são o controle da microbiota intestinal; estabilização da microbiota intestinal após o uso de antibióticos; promoção da resistência gastrintestinal à colonização por patógenos; diminuição da população de patógenos através da produção de ácidos acético e lático, de bacteriocinas e de outros compostos antimicrobianos; promoção da digestão da lactose em indivíduos intolerantes; estimulação do sistema imune; alívio da constipação; aumento da absorção de minerais e produção de vitaminas (SHAH; LANKAPUTHRA, 1997).

Deve-se enfatizar que os micro-organismos probióticos, não podem ser patogênicos e que seu efeito benéfico para o hospedeiro via balanço da microbiologia intestinal, estão correlacionados com a quantidade ingerida e sugerida na faixa entre $10^{5}$ a $10^{6}$ células viáveis por $\mathrm{mL}$ ou $\mathrm{g}$ de produto (GRANATO et al., 2010; SAAD, 2006). A Agência Nacional de Vigilância Sanitária recomenda que para um alimento ser considerado probiótico e atuar no equilíbrio da microbiota intestinal, este deve apresentar quantidade mínima viável para estes micro-organismos na faixa de $10^{8}$ a $10^{9}$ UFC por porção consumida do produto (ANVISA, 2008). Essa quantidade mínima de probióticos deve ser considerada alta, para compensar uma possível redução no número de micro-organismos durante a passagem pelo estômago e intestino (SHAH, 2000).

Leites fermentados e iogurtes são os produtos probióticos mais tradicionais e consumidos, entretanto, os queijos podem ser uma boa alternativa de matriz para estes micro-organismos devido ao seu maior $\mathrm{pH}$, conteúdo de gordura, nível de oxigênio, condições de estocagem e por ter uma matriz sólida, podendo proteger o microorganismo probiótico com maior eficácia durante o armazenamento do alimento e durante sua passagem pelo trato gastrointestinal (STANTON et al., 1998). Entretanto, a influência das etapas do processamento sobre a sobrevivência dos probióticos deve ser levada em consideração (GRANATO et al., 2010).
A adição de probióticos em requeijão cremoso foi avaliada por Drunkler, Sene e Oliveira (2005). Os autores produziram um requeijão cremoso adicionado de Bifidobacterium animalis subsp. lactis $\mathrm{Bb}-12$ e observaram a manutenção da contagem do micro-organismo probiótico em $10^{6} \mathrm{UFC} / \mathrm{g}$ durante 60 dias de armazenamento. As características sensoriais do produto também não foram alteradas quando comparadas ao requeijão controle.

Ramírez et al. (2007) desenvolveram um requeijão cremoso com adição de Lactobacillus

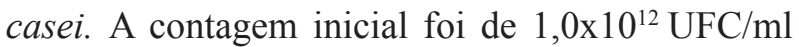
e após 15 dias diminuiu para $1,1 \times 10^{9} \mathrm{UFC} / \mathrm{ml}$. Os autores relacionaram a diminuição da contagem do L. casei ao armazenamento do produto sob refrigeração.

Tendo em vista o aumento do consumo de alimentos com adição de probióticos devido à percepção do consumidor por seus benefícios à saúde, o objetivo deste trabalho foi a elaboração de um requeijão probiótico e avaliação da viabilidade do Lactobacillus casei, composição físico-química e aceitação sensorial do produto.

\section{Material e Métodos}

Obtenção da massa para preparo do requeijão cremoso

A massa foi obtida pelo aquecimento do leite desnatado pasteurizado até a temperatura de $45^{\circ} \mathrm{C}$ e coagulação com o ácido láctico $85 \%(0,8 \% \mathrm{v} / \mathrm{v})$. O leite foi mantido sob agitação lenta e contínua até completa mistura do ácido lático, seguida de repouso até haver a precipitação da massa. Em seguida, foi feita a dessora com auxílio de pano de algodão e duas lavagens com água filtrada até que a massa atingisse o $\mathrm{pH}$ 5,2. A massa triturada e os demais ingredientes foram pesados conforme a seguinte formulação: $40,7 \%$ de massa, $37,7 \%$ de creme de leite pasteurizado com $35 \%$ de gordura, $0,6 \%$ de cloreto de sódio, $0,6 \%$ de sal fundente e $20,3 \%$ de água filtrada. 
Após a pesagem dos ingredientes foi realizada a fusão da massa. A massa, o sal fundente, cloreto de sódio e metade do creme de leite foram misturados e aquecidos $\left(90 \pm 1^{\circ} \mathrm{C}\right)$ até completa fusão, quando então foi adicionado o restante do creme de leite e a água. Após 5 minutos de cozimento, o aquecimento foi interrompido e o requeijão foi dividido em duas partes de iguais. A primeira parte do requeijão foi embalada em recipientes de polipropileno (300 g) devidamente higienizados, tampados e armazenados em BOD a $4 \pm 1^{\circ} \mathrm{C}$ e correspondeu ao requeijão controle. A segunda parte foi resfriada à temperatura de $50 \pm 1^{\circ} \mathrm{C}$ para a adição do probiótico Lactobacillus casei (LC-11, Danisco, Dinamarca).

A cultura probiótica foi adicionada na massa fundida conforme metodologia descrita por Drunkler et al. (2009) com adaptações. O Lactobacillus casei foi pré-ativado em leite em pó desnatado (reconstituído à 12\%) e incubado à $45^{\circ} \mathrm{C} / 3 \mathrm{~h}$. O inóculo foi adicionado no requeijão a $50^{\circ} \mathrm{C}$, na concentração de $0,5 \mathrm{~g} / 100 \mathrm{~g}(\mathrm{p} / \mathrm{p})$. Após a homogeneização da cultura, o requeijão adicionado de probiótico foi embalado em recipientes de polipropileno e armazenado nas mesmas condições que o requeijão controle.

\section{Análises físico-químicas e microbiológicas}

O leite desnatado utilizado nos processamentos foi avaliado quanto ao $\mathrm{pH}$, acidez, umidade, cinzas, nitrogênio total (AOAC, 1995) e gordura (BRITISH STANDARD INSTITUTION, 1989). Após o $1^{\circ}$ dia de fabricação, o requeijão controle e o adicionado de probiótico foram avaliados quanto ao $\mathrm{pH}$, acidez, umidade, cinzas, nitrogênio total (AOAC, 1995), gordura pelo método de Gerber (BRITISH STANDARD INSTITUTION, 1989) e sal pelo método de Volhard (RICHARDSON, 1985). O pH das amostras com e sem adição de probiótico foi avaliado após 1, 7, 14 e 28 dias armazenamento. As análises físico-químicas foram realizadas em triplicata.
Para avaliação da viabilidade do microorganismo probiótico durante o armazenamento refrigerado, o requeijão que sofreu sua adição foi avaliado quanto à contagem de $L$. casei após 1,7 , 14 e 28 dias. A contagem de Lactobacillus casei foi realizada segundo metodologia descrita por Rogosa, Mitchell e Wiseman (1951). Alíquotas de 25 g de amostra foram transferidas para bolsas estéreis, onde foram adicionados $225 \mathrm{~mL}$ de citrato de sódio $2 \%$. A mistura foi homogeneizada e imediatamente utilizada para a análise microbiológica. A partir desta primeira diluição, foram efetuadas as diluições decimais subsequentes em água peptonada $0,1 \%$. A contagem foi realizada em Rogosa SL agar (HiMedia Laboratories, India), pelo método de plaqueamento em profundidade com sobrecamada, em duplicata, incubando as placas a $37^{\circ} \mathrm{C} / 72$ horas.

\section{Análise sensorial}

Para a realização da avaliação sensorial foram recrutados 56 provadores não treinados, aleatoriamente. Os requeijões probiótico e controle foram avaliados após 4 dias de armazenamento refrigerado. As amostras $(\sim 25 \mathrm{~g})$ foram servidas à aproximadamente $7^{\circ} \pm 1 \mathrm{C}$ em copos plásticos codificados com números aleatórios de 3 dígitos e submetidas à avaliação sensorial dos atributos aparência, sabor, aroma, textura e aceitação geral utilizando escala hedônica estruturada de nove pontos onde "1-desgostei muitíssimo" e "9-gostei muitíssimo". Os requeijões foram avaliados também quanto à intenção de compra utilizando a escala estruturada onde "1-certamente compraria" e "5-certamente não compraria" (MEILGAARD; CIVILLE; CARR, 2006).

\section{Delineamento experimental e avaliação estatística}

O delineamento experimental utilizado foi o de parcelas subdivididas (split-plot) em blocos e foram realizadas 2 repetições completas do experimento. O efeito dos tratamentos (controle e adicionado de 
probiótico), do tempo de armazenamento (1, 7, 14 e 28 dias), bem como da interação destes fatores sobre o $\mathrm{pH}$ e a contagem de Lactobacillus casei foi avaliado por análise de variância (ANOVA) e teste de médias de Tukey ao nível de 5\% de significância.

Os resultados da avaliação sensorial foram avaliados por Análise de Variância (ANOVA), ao nível de significância de 5\%, e teste de médias de Tukey. Os resultados do teste de intenção de compra foram transformados em porcentagem e analisados através de um histograma de frequências. Todos os resultados foram avaliados utilizando o programa Statistica 8.0 (Stat Soft, Inc).

\section{Resultados e Discussão}

Composição físico-química do leite e do requeijão

O leite desnatado pasteurizado apresentou composição característica e dentro dos padrões estabelecidos pela IN no 62/2011 (BRASIL, 2011) que são: máximo de $0,5 \%$ de gordura e acidez entre $14-18^{\circ} \mathrm{D}$. Os valores médios de $\mathrm{pH}$, acidez, gordura, extrato seco total, cinzas e proteína total foram, respectivamente: $6,94 \pm 0,28 ; 18 \pm 2{ }^{\circ} \mathrm{D} ; 0,4 \pm 0,1 \%$; $9,0 \pm 0,7 \% ; 0,76 \pm 0,05 \%$ e $2,56 \pm 1,24 \%$.

A Tabela 1 apresenta a composição físicoquímica dos requeijões controle e adicionado de probiótico e a contagem de Lactobacillus casei do requeijão probiótico após 1 dia de fabricação. Quanto à composição não foram observadas diferenças significativas entre os requeijões, mostrando que a adição do probiótico não influenciou na característica físico-química do produto. A composição de ambas as amostras atendeu aos requisitos da legislação (BRASIL, 1997) que são umidade máxima de $65 \%$ e gordura em base seca (GBS) mínima de 55\%.

Tabela 1. Composição físico-química e microbiológica do requeijão.

\begin{tabular}{lccc}
\hline & \multicolumn{3}{c}{ Média \pm desvio padrão } \\
\cline { 2 - 4 } & Controle & Probiótico & Valor de $\boldsymbol{P}$ \\
\hline $\mathrm{pH}$ & $5,74 \pm 0,69^{\mathrm{a}}$ & $5,79 \pm 0,68^{\mathrm{a}}$ & 0,8875 \\
Acidez (\% ácido láctico) & $0,63 \pm 0,13^{\mathrm{a}}$ & $0,65 \pm 0,15^{\mathrm{a}}$ & 0,7248 \\
Umidade (\%) & $62 \pm 8^{\mathrm{a}}$ & $63 \pm 6^{\mathrm{a}}$ & 0,7434 \\
Gordura (\%) & $22 \pm 5^{\mathrm{a}}$ & $22 \pm 5^{\mathrm{a}}$ & 0,8583 \\
Gordura em base seca (\%) & $58 \pm 2^{\mathrm{a}}$ & $61 \pm 4^{\mathrm{a}}$ & 0,1635 \\
Cinzas (\%) & $1,8 \pm 0,5^{\mathrm{a}}$ & $1,8 \pm 0,5^{\mathrm{a}}$ & 0,8818 \\
Proteína Total (\%) & $13,2 \pm 2^{\mathrm{a}}$ & $14,7 \pm 3^{\mathrm{a}}$ & 0,4155 \\
Sal (\%) & $0,8 \pm 0,2^{\mathrm{a}}$ & $0,8 \pm 0,3^{\mathrm{a}}$ & 0,9725 \\
Lactobacillus casei (UFC/g) & ---- & $2,2 \times 10^{7}$ & ---- \\
\hline
\end{tabular}

${ }^{\mathrm{a}, \mathrm{b}}$ Médias com letras iguais na mesma linha não diferem significativamente entre si $(\mathrm{P}>0,05)$.

Fonte: Elaboração dos autores.

A contagem média de Lactobacillus casei do inóculo utilizado para produção do requeijão probiótico foi de $3,3 \times 10^{7} \mathrm{UFC} / \mathrm{g}$. Levando-se em consideração a contagem inicial de $2,2 \times 10^{7} \mathrm{UFC} / \mathrm{g}$ 1 dia após o processamento, pode-se concluir que as condições do processamento não influenciaram na sobrevivência do Lactobacillus casei.
A Agência Nacional de Vigilância Sanitária (ANVISA, 2008) estabelece que para um alimento ser considerado probiótico e atuar no equilíbrio da flora intestinal, este deve apresentar quantidade mínima viável para estes micro-organismos na faixa de $10^{8}$ a $10^{9}$ células viáveis por porção do 
produto (ANVISA, 2008). A informação nutricional dos requeijões tradicionais comercializados no Brasil é calculada com base em porções de $30 \mathrm{~g}$. Portanto, o consumo desta quantidade $(30 \mathrm{~g})$ do requeijão probiótico elaborado neste trabalho fornece $\sim 10^{8}$ UFC do Lactobacillus casei, podendo assim ser considerado como probiótico. Apesar da recomendação da legislação brasileira, diversos autores recomendam que produtos com contagem de probióticos entre $10^{6}$ e $10^{7} \mathrm{UFC} / \mathrm{g}$ ou $\mathrm{mL}$ podem ser considerados probióticos e apresentar o efeito benéfico à saúde (GRANATO et al., 2010; SAAD, 2006).
Efeito do tempo sobre o $\mathrm{pH}$ e contagem de Lactobacillus casei do requeijão

O tratamento $(P=0,7425)$, o tempo de armazenamento $(P=0,3835)$ e a interação entre estes fatores $(P=0,9379)$ não influenciaram o $\mathrm{pH}$ dos requeijões. Observa-se na Figura 1 que o $\mathrm{pH}$ das amostras manteve-se constante durante todo o armazenamento e variou-se de 5,7 para 5,6 no requeijão controle e de 5,8 para 5,4 no requeijão probiótico, mantendo-se dentro do $\mathrm{pH}$ normal para requeijão segundo Oliveira (1990).

A contagem de Lactobacillus casei não foi influenciada pelo tempo de armazenamento $(P=0,8202)$ e não apresentou variações significativas durante os 28 dias de análise (Figura 2), mostrando que o requeijão é uma matriz adequada para a adição de probióticos e pode ser caracterizado durante o tempo de análise deste experimento como probiótico.

Figura 1. Variação do pH durante o tempo de armazenamento.

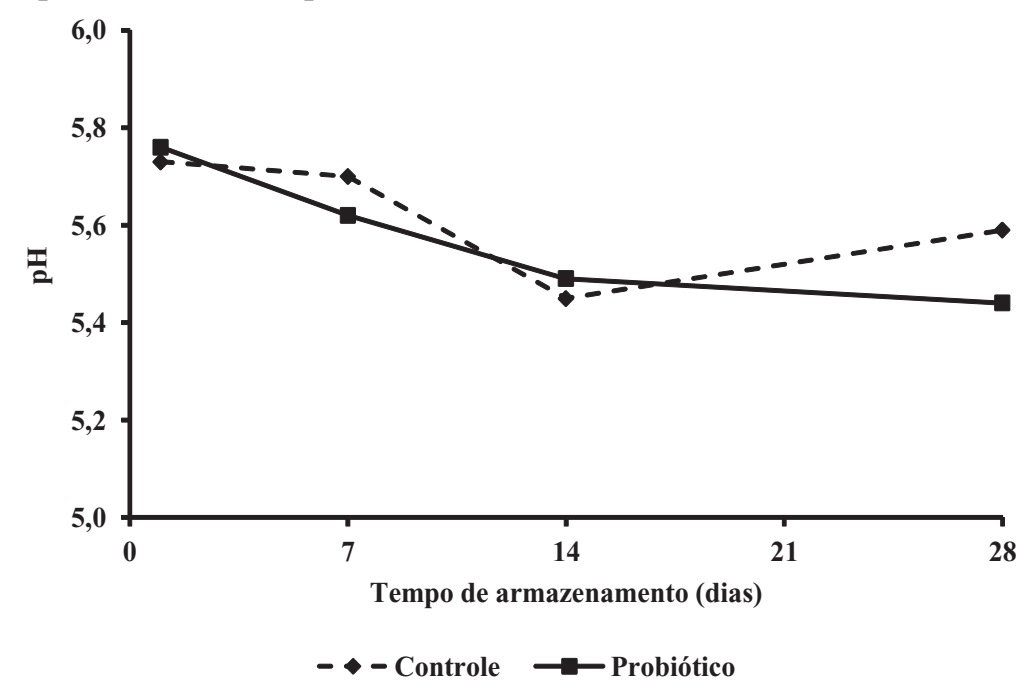

Fonte: Elaboração dos autores. 
Figura 2. Contagem de Lactobacillus casei durante o armazenamento do requeijão probiótico.

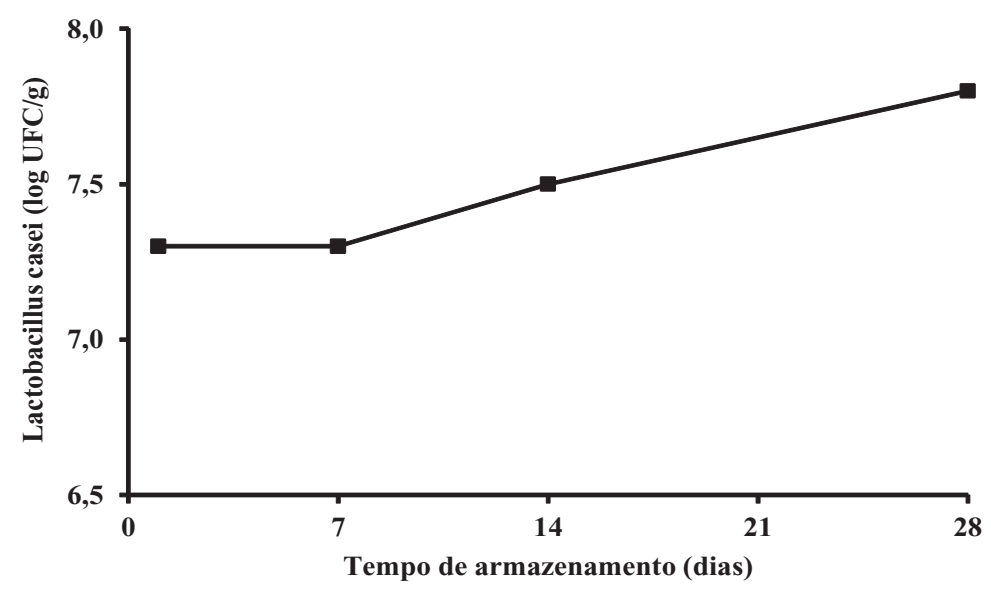

Fonte: Elaboração dos autores.

\section{Avaliação sensorial}

A Tabela 2 apresenta as médias das notas atribuídas pelos provadores para o requeijão controle e adicionado de Lactobacillus casei. Sendo o Lactobacillus casei um micro-organismo com características proteolíticas, sua adição poderia influenciar no sabor e na textura do requeijão, provocando a rejeição dos provadores. Entretanto, os resultados mostraram que a adição do probiótico não influenciou significativamente as características sensoriais do produto. As notas para aparência, aroma, sabor, textura e aceitação geral do requeijão probiótico estiveram entre gostei moderadamente (nota 7) e gostei muito (nota 8) na escala de avaliação sensorial.

Tabela 2. Notas médias da avaliação sensorial do requeijão cremoso.

\begin{tabular}{lccc}
\hline & Controle & Probiótico & Valor de $\boldsymbol{P}$ \\
\hline Aparência & $8,3^{\mathrm{a}}$ & $8,3^{\mathrm{a}}$ & 0,7974 \\
Aroma & $7,7^{\mathrm{a}}$ & $7,5^{\mathrm{a}}$ & 0,8553 \\
Sabor & $7,5^{\mathrm{a}}$ & $7,7^{\mathrm{a}}$ & 0,4364 \\
Textura & $8,0^{\mathrm{a}}$ & $8,2^{\mathrm{a}}$ & 0,2608 \\
Aceitação Geral & $7,6^{\mathrm{a}}$ & $7,7^{\mathrm{a}}$ & 0,4603 \\
\hline
\end{tabular}

${ }^{\mathrm{a}, \mathrm{b}}$ Médias com letras iguais na mesma linha não diferem significativamente entre si $(\mathrm{P}>0,05)$.

Fonte: Elaboração dos autores.

A Figura 3 apresenta a intenção de compra do requeijão controle e probiótico e mostra que $\sim 82 \%$ dos provadores certamente ou provavelmente comprariam o requeijão probiótico, enquanto para o requeijão controle esta porcentagem foi de $72 \%$. Estes resultados mostram a boa aceitação do requeijão probiótico pelos potenciais consumidores. 
Figura 3. Intenção de compra do requeijão controle e probiótico

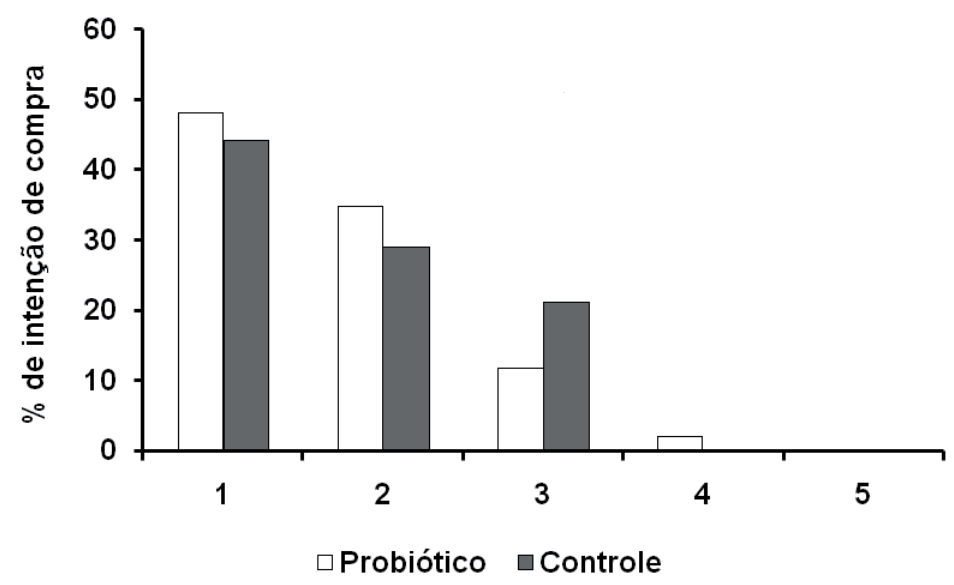

Fonte: Elaboração dos autores.

\section{Conclusão}

Acomposição físico-química não foi alterada com a adição do probiótico e a contagem de Lactobacillus casei se manteve constante ao longo de 28 dias de armazenamento refrigerado do produto e na ordem de $10^{7} \mathrm{UFC} / \mathrm{g}$, podendo o requeijão ser considerado como probiótico. As características sensoriais do requeijão probiótico não foram influenciadas, já que o produto apresentou boa aceitação e intenção de compra de $82 \%$ dos provadores. Desta forma, com base nos resultados, o requeijão cremoso apresentase como um produto adequado para a adição de micro-organismos probióticos.

\section{Referências}

AGÊNCIANACIONALDE VIGILÂNCIA SANITÁRIA - ANVISA. Alimentos com alegações de propriedades funcionais e ou de saúde, novos alimentos/ingredientes, substâncias bioativas e probióticos. IX - Lista de alegações de propriedade funcional aprovadas. 2008. Disponível em: <http://www.anvisa.gov.br/alimentos/ comissoes/tecno_lista_alega.htm>. Acesso em: 03 mar. 2012.

ASSOCIATION OF OFFICIAL ANALYTICAL CHEMISTS - AOAC. Official methods of analysis of AOAC International. 16. ed. Gaithersburg, Maryland: AOAC International, 1995.
BRASIL. Ministério da Agricultura, Pecuária e Abastecimento. Departamento de Inspeção de Produtos de Origem Animal. Instrução Normativa n ${ }^{\circ} 62$, de 29 de dezembro de 2011. Alteração da Instrução Normativa ${ }^{\circ}$ 51. Diário Oficial [da] República Federativa do Brasil, n. 251, p. 6-11, 30 dez. 2011 a. Seção 1.

. Regulamento técnico de identidade e qualidade do requeijão. Portaria $\mathrm{n}^{\mathrm{0}} 359$ de 04 de setembro de 1997. Disponível em: <http://extranet.agricultura.gov. $\mathrm{br} /$ sislegis/action/detalhaAto.do?method=consultarLegis lacaoFederal>. Acesso em: 04 mar. 2012.

BRITISH STANDARDS INSTITUTION. Determination offat content of milk and milk products (Gerber methods). Methods. London: British Standards Institution, 1989. 12 p.

DRUNKLER, D. A.; ISHIHARA, R. Y.; GRAFF, A. I.; DALCIN, D.; FARIÑA, L. O.; KASKANTZIS NETO, G. Padronização da metodologia de adição de probióticos em requeijão cremoso. Revista Higiene Alimentar, São Paulo, v. 170-171, n. 23, p. 524-525, 2009.

DRUNKLER, D. A.; SENE, L.; OLIVEIRA, L. F. Probióticos, prebióticos e simbióticos: alimentos funcionais em ascensão. Revista do Instituto de Laticínios Cândido Tostes, Juiz de Fora, v. 60, n. 343, p. 29-38, 2005.

FOOD AND AGRICULTURE ORGANIZATION OF THE UNITED NATIONS, WORLD HEALTH ORGANIZATION - FAO/WHO. Probiotics in food: health and nutritional properties and guidelines for evaluation. Roma, Itália: Food and Agriculture Organization of the United Nations, World Health Organization, 2006. 56 p. 
FOX, P. F.; GUINEE, T. P.; COGAN, T. M.; McSWEENEY, P. L. H. Fundamentals of cheese science. Gaithersburg Maryland: Aspen Publishers, Inc. 2000. 587 p.

GRANATO, D.; BRANCO, G. F.; CRUZ, A. G.; FARIA, J. de A. F.; SHAH, N. P. Probiotic dairy products as functional foods. Comprehensive Reviews in Food Science and Food Safety, Malden, v. 9, n. 5, p. 455-470, 2010.

MEIlGAARD, M.; CIVILlE, G. V.; CARR, B. T. Sensory evaluation techniques. 4. ed. Boca Raton: CRC Press, 2006. 448 p.

OLIVEIRA, J. S. Queijos: fundamentos tecnológicos. Campinas: Ícone, 1990. 146 p.

OLIVEIRA, M. N.; SIVIERI, K.; ALEGRO, J. H. A.; SAAD, S. M. I. Aspectos tecnológicos de alimentos funcionais contendo probióticos. Revista Brasileira de Ciências Farmacêuticas, São Paulo, v. 38, n. 1, p. 1-21, 2002.

RAMÍREZ, L. A. G.; OSPINA, A. J. G.; JARAMILLO, L. M. A.; PATIÑO, B. T. Evaluación de la viabilidad de una cepa probiótica nativa de Lactobacillus casei en queso crema. Revista Lasallista de Investigación, Antioquia, v. 4, n. 2, p. 37-42, 2007.
RICHARDSON, G. H. Standard methods for examination of dairy products. Washington: American Public Health Association, 1985. $412 \mathrm{p}$.

ROGOSA, M., MITCHELL, J. A.; WISEMAN, R. F. A selective medium for the enumeration of oral and faecal lactobacilli. Journal of Bacteriology, Washington, v. 62, n. 1, p. 132-133, 1951.

SAAD, S. M. I. Probióticos e prebióticos: o estado da arte. Revista Brasileira de Ciências Farmacêuticas. São Paulo, v. 42, n. 1, p. 1-16, 2006.

SHAH, N. P. Probiotic bacteria: selective enumeration and survival in dairy foods. Journal of Dairy Science, Madison, v. 83, n.4, p. 894-907, 2000.

SHAH, N. P.; LANKAPUTHRA, W. E. V. Improving viability of Lactobacillus acidophilus and Bifidobacterium spp. in yogurt. Internacional Dairy Journal, Barking, v. 7, n. 5, p. 349-356, 1997.

STANTON, C.; GARDINER, G.; LYNCH, P. B; COLlinS, J. K.; FITZGERALD, G.; ROSS, R. P.; Probiotic cheese. International Dairy Journal, Barking, v. 8, n. 5, p. 491-496, 1998.

WALSTRA, P.; WOUTERS, J. T. M.; GEURTS, T. J. Dairy science and technology. Boca Raton: CRC Press, 2006. 762 p. 
